\title{
Methodology of passenger public transport organization within the context of long-term territorial development of a city
}

\author{
Aleksandr Novikov ${ }^{1}$, Sergey Eremin ${ }^{2}$, and Andrei Kulev ${ }^{1 *}$ \\ ${ }^{1}$ Orel State University, 302026 Orel, Komsomolskaya st. 95, Russian Federation \\ ${ }^{2}$ Krasnoyarsk City Administration, 660049 Krasnoyarsk, Karl Marks str., 93, Russian Federation
}

\begin{abstract}
The article presents selected scientific approaches based on multi-criteria optimization which can be applied for the organization of passenger public transport within the context of long-term territorial development of the city. The transport network of the city of Krasnoyarsk was chosen as an example for the presentation of practical application of these approaches.
\end{abstract}

\section{Introduction}

According to certain experts, the planning stage of transport infrastructure development lacks due attention and is frequently neglected in the current practice of territorial and urban planning in Russia. Amongst the reasons causing such a situation, there are both ones specific to our country and the rest that are typical for other countries [1-6].

Currently, in developed countries in particular, the methodology for the development of transport systems is based on the application of an integrated transport planning approaches, as well as on the mutually subordinated regulatory mid- and long-term planning documents for the development of transport systems in cities and regions. Integrated transport planning implies taking into account numerous aspects when conceiving projects for development of the transport system (Figure 1).

The process of integrated transport planning is based on multi-level strategic planning, which implies an integrated approach to solving the existing problems of the transport system of the city and the region, as well as forecasting and ensuring sustainable development in a long term [7-10].

Planning process has the following structure:

- $\quad$ short-term planning;

- $\quad$ addressing problems with the highest priority;

- elimination of bottlenecks related to throughput;

- mid-term and long-term planning;

- conception of functional and reliable transport system;

- $\quad$ addressing the negative effects of road traffic;

\footnotetext{
* Corresponding author: andrew.ka@mail.ru
} 
- forecasting and anticipating possible structural changes in the future.

\section{Aspect of urban planning}

- Sustainable urban development and promotion of "shared space" approach

\section{Economic aspect}

- Mathematical analysis of the costs and benefits of infrastructure development

\section{Transport aspect}

- Elimination of unnecessary traffic and simultaneous improvement of traffic flow conditions.

Shifting passenger flows towards sustainable modes of transport

\section{Social aspect}

- Designing the city environment that is convenient for everyone, with clean air and quiet streets

\section{Political aspect}

- Consensus of business, society and government when making transport-related decisions

Fig. 1. Aspects of integrated transport planning

\section{Materials and methods}

The main objective is to find an optimal solution when planning residential areas and implementing respective transport infrastructure, which must fulfill the generated demand and meet the standards of transport accessibility.

The formulation of the problem of a transport scheme selection implies taking into consideration a set of different criteria. When applying these criteria, it is necessary to introduce quantitative scales that determine reliability or risk, which makes the problem less formalized. As a result, modern formalization methods to solve such problems have to be determined and then put into practice.

In general case, the multicriteria optimization problem is formulated as follows:

$$
y_{i}=f_{i}(x) \rightarrow \max , i=1 . . n x \in D,
$$

Analysis of the effectiveness of the solution uses the Pareto relation:

$$
\left\{\forall x_{1}, x_{2} \in \Omega\right\} x_{1} P x_{2} \Leftrightarrow\{\forall i=1 . . n\} x_{1 i} \geq x_{2 i} \cap \exists j 0: x_{1 j 0}>x_{2 j 0}
$$

Or in general case:

$$
P(\Omega)=y \in \Omega \forall \neg\left(y^{\prime} P x\right)
$$

The Pareto set does not provide a defined solution, but only creates an effective frontier. Therefore, in practice, criteria weighting procedures are mainly used.

The method of successive concessions can be used as one of the approaches. In this situation, the indicators are ranked in order of importance $f_{1}, f_{2}, \ldots, f_{n}$, with the assumption that they have to be maximized.

The optimization problem to be solved is presented in the following manner: $X^{*}=\arg \max _{x \in D} f_{1}(X) \quad f^{*}{ }_{l}\left(X^{*}\right)=f^{*}{ }_{1}$. Then, based on practical considerations and the 
accuracy of the initial data (which is usually low), a certain concession $\Delta f_{l}$ is assigned, which we accept in order to maximize the criteria $f^{*}{ }_{2}$ and to solve the problem $f_{2} \rightarrow \max f_{1}>f^{*}{ }_{1}-\Delta f_{1}$. A list of all residential areas' development projects is compiled, ranked by profitability and then a concession assignment is made.

After that, we proceed to solving the problem $X^{*}{ }_{1}=\arg \max _{x \in D_{1}} f_{2}(X) D_{I}=\{X: X \in D$, $\left.f_{l}\left(X^{*}\right)=f^{*}-\Delta f_{l}\right\}$. An option of the most rational solution of transport infrastructure developments is being selected.

The procedure is iteratively repeated for each of the criteria in the order of significance: $X_{k}^{*}=\arg \max _{x \in D_{k-1}} f_{2}(X) D_{k}=\left\{X: X \in D_{k-1}, f_{k}\left(X^{*}\right)=f^{*}{ }_{k}-\Delta f_{k}\right\}$.

As a rule, in the vicinity of the maximum of one criterion, its functionality with respect to the other is quadratic; hence, the increase in the second criterion is way greater than the concession which was made.

\section{Results and Discussion}

During the analysis of the transport system of the city of Krasnoyarsk, the main identified problems of the transport network are the following:

1. Significant duplication of public transport (PT) routes (3-4 routes from each district to the center)

2. Routes duplication of rail (tram) and road transport

3.Presence of so-called "tennis racket" routes (one-way detours without bi-directional communication)

4. Low occupancy rate of high-capacity vehicles, loss-making and redundant network

5. Low occupancy rate entails inefficiencies and imbalances:

- "unprofitable" long routes to remote areas with low passenger turnover - overloaded

- "profitable" short routes with intense passenger turnover - they run half-empty, consuming resources unnecessarily.

To solve these problems, it is envisaged to broaden the coverage of the area where new residential areas are planned with a new route network of urban public transport (Figure 2).

Within the framework the general reorganization project, it is planned to cancel 14 public transport routes and change 48 routes, including 3 "green"-routes on which run vehicles using sustainable energy sources. Yet, to improve the quality of transport services for the population and increase the speed of communication, $55.8 \mathrm{~km}$ of dedicated public transport lanes will be organized. 


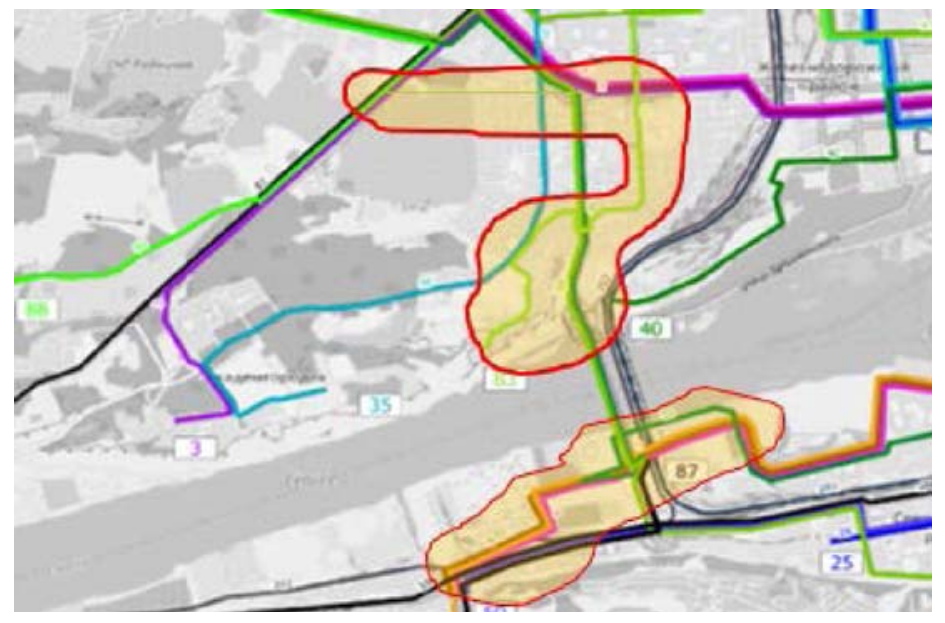

Fig. 2. Coverage of the planned residential areas by the new route network of urban public transport

The auxiliary tools and systems for management and decision-making in the field of organizing passenger traffic in the city of Krasnoyarsk include: a) the installation of 506 traffic lights, b) 240 sensors and detectors for monitoring traffic flows' intensity, c) 1328 sensors for an automated navigation system for dispatch control, d) 65 sensors for an automated system monitoring passenger flows, e) 86 video cameras of the automated system "Safe City".

Changes in the number of rolling stock on public transport routes imply primarily a decrease in the total number of vehicles due to a more rational distribution of vehicles between routes (Table 1).

Table 1. Dynamics of changes in the number of rolling stock on the public transport routes of the city of Krasnoyarsk

\begin{tabular}{|c|c|c|}
\hline Vehicle class & $\begin{array}{c}\text { Initial state of the route network of } \\
\text { the city of Krasnoyarsk }\end{array}$ & $\begin{array}{c}\text { Planned state of the route network } \\
\text { of the city of Krasnoyarsk }\end{array}$ \\
\hline Small, units & 41 & 45 \\
\hline Medium, units & 312 & 405 \\
\hline Large, units & 643 & 480 \\
\hline Total, units & 996 & 930 \\
\hline
\end{tabular}

The planned changes will also affect the reachability of public transport stops. The construction of new public transport stops will be organized firstly in areas with a low level of transport accessibility. The scheme of pedestrian accessibility of PT stops in the planned urban public transport network of Krasnoyarsk is shown in Figure 3. 


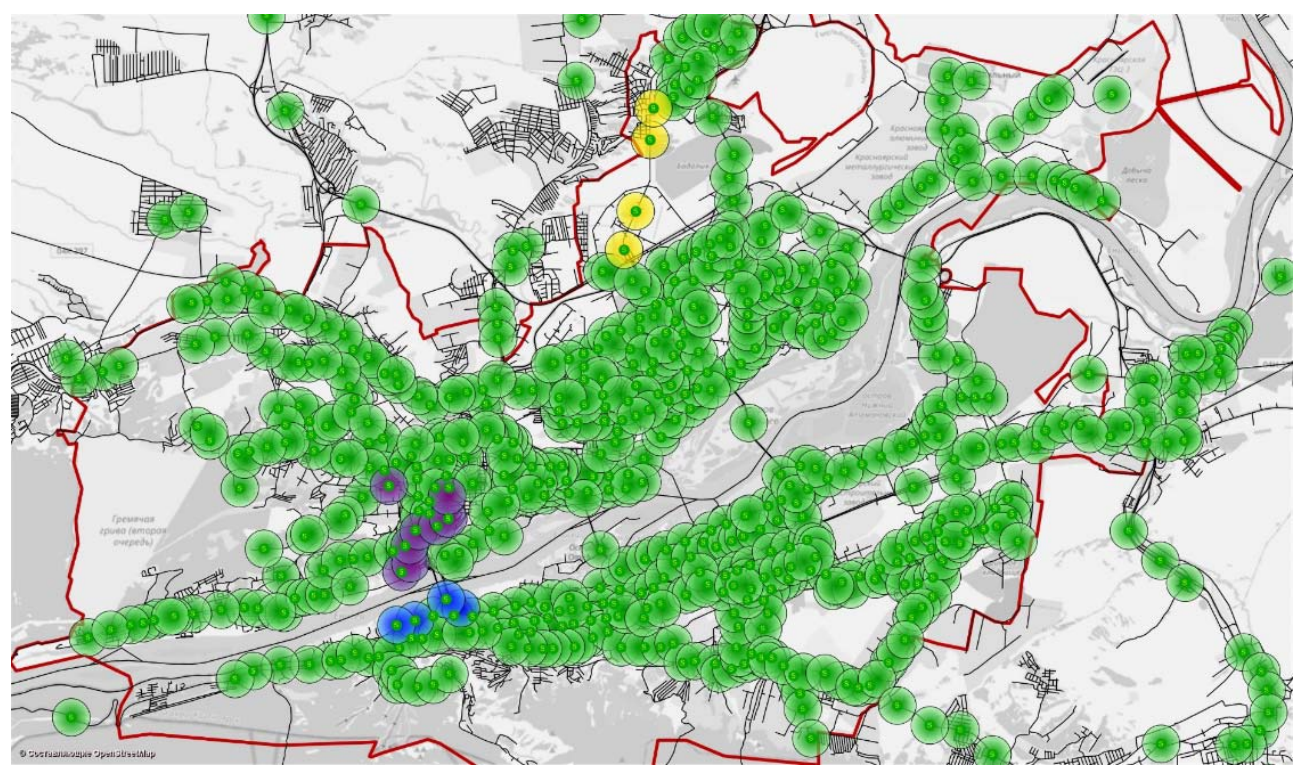

Fig. 3. The scheme of pedestrian accessibility of PT stops in the planned urban public transport network of Krasnoyarsk

\section{Conclusion}

As a result of the proposed measures, it is proposed to reduce the number of public transport routes from 74 to 68 . At the same time, it is planned to reduce the length of the route network from $1746.8 \mathrm{~km}$ to $1550.6 \mathrm{~km}$. Furthermore, the estimated average traffic speed would increase from 16.5 to $20.4 \mathrm{~km} / \mathrm{h}$ and the number of accidents should drop from 48 to 40 per year.

\section{References}

1. D. Lomakin, A. Bodrov, M. Kulev, and A. Kulev, Improvement of road traffic management system on the basis of mathematical and simulation modeling, MATEC Web of Conferences, vol. 298, p. 00045 (2019).

2. A. Novikov, S. Eremin, and A. Kulev, Formation of recommendations for the selection of types of connections for different types of crossroads based on the generalized imitation model, MATEC Web of Conferences, vol. 298, p. 00047 (2019)

3. M. V. Kulev, A. V. Kulev, and N. S. Kuleva, Efficiency assessment in transport service provision for the population of Orel city, IOP Conference Series: Materials Science and Engineering, vol. 971, p. 052090 (2020)

4. A. Marusin, A. Marusin, and I. Danilov, A method for assessing the influence of automated traffic enforcement system parameters on traffic safety, Transportation Research Procedia, vol. 36, pp. 500-506 (2018)

5. A. Gorev, A. Solodkiy, and V. Enokaev, Improving efficiency of traffic management and safety based on integration of local ATMS, Transportation Research Procedia, vol. 36, pp. 207-212 (2018)

6. H. T. Dimitriou, Urban public transport and economic development, Sustainable Approaches to Urban Transport, pp. 187-192 (2019) 
7. D. Mohan, Safety and Sustainable Urban Transport, Urban Transport Development, pp. 279-291.

8. H. Örn, Urban Public Transport in an International Perspective, Urban Transport Development, pp. 45-64.

9. M. Jacyna and P. Kotylak, Decision-Making Problems of Collective Transport Development in Terms of Sustainable Urban Mobility, Journal of KONBiN, vol. 50, no. 2, pp. 359-375 (2020).

10. V. Vdovychenko, FUZZY PRODUCTION MODEL OF URBAN PUBLIC PASSENGER TRANSPORT SUSTAINABLE DEVELOPMENT, Automobile Transport, vol. 0, no. 41, p. 91, Nov. 2017. 